DOI: $10.29327 / 217579.5 .1-13$

\title{
GAROTAS DE PROGRAMA EM TERESINA: PRODUÇÕES DO CORPO NO CONTEXTO DA PROSTITUIÇÃO
}

\author{
Women prostitutes in Teresina: Body production \\ in the context of prostitution
}

Marcos Paulo Magalhães de Figueiredo ${ }^{139}$

\begin{abstract}
Resumo:
Ainda distante de ser encarado como um trabalho formal, a prostituição ainda é o meio de sobrevivência encontrado por muitas pessoas entre estas mulheres. A partir da premissa de que o corpo é a ferramenta de trabalho utilizada na prostituição analisaremos a luz de Mauss (2017), Le Breton (2006; 2016) como garotas de programa na região Centro-sul de Teresina produzem e usam seus corpos para o trabalho na prostituição e com qual a finalidade. Para a realização da pesquisa foram aplicados questionários semiestruturados em conjunto com um trabalho de campo que possibilitou observar o cotidiano das garotas participantes. O trabalho mostra como ao produzir-se para prostituição fatores econômicos e subjetivos misturam-se produzindo um corpo momentâneo para a prostituição.
\end{abstract}

Palavras-chave: Prostituição feminina; Corpo; Produção corporal

\begin{abstract}
:
Still far from being seen as a formal job, prostitution is a way of survival pursued by many people, mostly women. From the premise that the body is the tool of work used in prostitution, we will analyze using Mauss (2017), Le Breton $(2006,2016)$ how prostitutes in the south downtown of Teresina produce and use their bodies for the work and with which goal. For the realization of the research were applied semi structured questionnaires together with a fieldwork that made possible to observe the daily lives of the participating girls. The work shows how economic and subjective factors are mixed producing a momentary body for prostitution.
\end{abstract}

Keywords: Female Prostitution; Body, Body Produce

\footnotetext{
${ }^{139}$ Licenciado em Ciências Sociais pela Universidade Federal do Piauí - UFPI. Mestrando em Antropologia pelo Programa de Pós-graduação em Antropologia pela Universidade Federal Do Piauí - UFPI. E-mail: marcospaulomagalhães25@gmail.com
} 


\section{Introdução}

O artigo apresentado é originário de uma pesquisa de monografia. Esta objetivou compreender a forma como mulheres prostitutas atuantes na região central de Teresina - PI produzem e constroem seus corpos para o trabalho na prostituição. A pesquisa identificou as motivações imbricadas das garotas entrevistadas ao produzir-se corporalmente quando inseridas no trabalho sexual, mais especificamente a prostituição.

A categoria analítica para verificar a produção corporal entre mulheres prostitutas de Teresina são aquelas com corpos inseridos na prostituição. $\mathrm{O}$ corpo de uma mulher inserido na prostituição seria aquele aonde o indivíduo é maior de dezoito anos e possui autonomia sobre seu trabalho na prostituição. Diferentemente do corpo prostituído, no qual, a garota é vista como vítima de tráfico ou exploração sexual de menores e/ou quando a maior parte dos ganhos é cooptado por rufiões ou aliciadores. (PISCITELLI 2005, 2013; MORAES, 2014).

O corpo enquanto objeto de estudo da sociologia e antropologia teve como seus primeiros exponentes os estudos de Marcel Mauss (2017), o autor comparava as diferentes técnicas e usos do corpo em várias culturas. As técnicas corporais usadas para dormir ou descansar, comer, andar e transar são construções culturais que paulatinamente vão sendo naturalizadas pelo sujeito. $\mathrm{O}$ trabalho consiste em uma sociologia do corpo, tendo como esforço não apenas o de descrever as condições da corporalidade das mulheres entrevistadas, mas, sim, consistindo em um esforço de centralizar o corpo e seus processos enquanto principal objeto de enfoque da pesquisa. (LE BRETON, 2006).

Trata-se de uma pesquisa qualitativa com a inserção durante sete dias em ruas e boates ${ }^{140}$ no Centro de Teresina. O trabalho de campo foi uma etapa importante da pesquisa, possibilitando acompanhar de maneira próxima o cotidiano de mulheres prostitutas durante sua inserção nas boates e/ou nas ruas. Tornando a participação, mesmo que por um período curto do cotidiano das mulheres que ali trabalhavam, foi um momento crucial para a realização da pesquisa. Com isso, foi viável acompanhar os discursos e conversas espontâneas que apareciam no local.

Em conjunto com o trabalho de observação no campo, foram realizadas entrevistas semiestruturadas durante a pesquisa nas boates. A aplicação destas deu-se de maneira individual nas boates aonde as garotas trabalhavam ou mesmo nas ruas da região. Em alguns momentos, durante as entrevistas surgiram convites das garotas para conhecer seus quartos, estes, que, são diferentes dos quartos usados para a realização do programa. Considera-se que entrevistas desse tipo possibilitem que as pessoas respondam mais com suas próprias palavras do que em entrevistas padronizadas, mas, ainda assim, forneçam uma estrutura maior de comparabilidade do que nas entrevistas focalizadas. As entrevistas foram realizadas com o auxílio de um gravador e depois transcritas, permitindo um melhor tratamento dos dados (MAY, 2001; BEAUD \& WEBER, 2014).

A pesquisa pretende através da observação do cotidiano das mulheres transeuntes no espaço pesquisado, e, com o uso de entrevistas semiestruturadas, reconstituírem a lógica e as motivações incrustadas que fazem com que garotas de programa invistam na produção cultural do próprio corpo. A escolha do uso das entrevistas em conjunto com o trabalho de campo, ocorreu devido aos limites do tempo para a realização da pesquisa. Assim, a fim de costurar os procedimentos metodológicos utilizados na pesquisa, busca-se interpretar os processos de construção do corpo enunciados pela fala das garotas através da teoria interpretativa de Clifford Geertz (2008). Para o autor, cultura é constituída de teias de significados inseridos em um contexto específico e feitas pelos próprios sujeitos da pesquisa. Em suma, aqui, irá tratar-se de explorar e interpretar o que as garotas de programa interpretam sobre si mesmas e sobre sua própria corporalidade.

\footnotetext{
${ }^{140}$ Escolheu-se por usar o termo "boate" ou "bar" ao invés de "bordel", pois em uma conversa com uma das donas de boate da região nos foi mostrado que os sentidos das palavras "cabaré" ou "bordel" estão relacionados com violência, uso de drogas e outros tipos de atividades tidas como ilícitas. Assim como, também, as prostitutas e outros trabalhadores referiam-se ao local como "boate".
} 
A entrada no campo foi mediada em conjunto com a Associação de Prostitutas do Piauí - APROSPI, isto, durante uma atividade de checagem de Infecções Sexualmente Transmissíveis (ISTs) e distribuição de preservativos e lubrificantes para as garotas que trabalhavam no local. A intermediação em conjunto com a APROSPI foi um fator decisivo para a entrada no campo, visto que, muitas das entrevistadas mostravam-se receosas ou desconfiadas em contribuírem para com a pesquisa.

Aconteceram cinco entrevistas com garotas de programa, sendo, três delas (Graça 28, Amélia 22 e Fátima 38) que trabalhavam em uma boate conhecida como Hilda Drink's; enquanto, que, as outras duas, uma garota (Ângela 27) trabalhava nas ruas em torno da boate, e, a outra (Rita 29) trabalhava no Bar da Geni. Houve dificuldades iniciais das garotas cederem entrevistas, sobretudo, em relação ao medo de serem identificadas. Muitas garotas falavam sobre si de forma corriqueira, mas, ainda assim, não concordavam em assinar o termo de consentimento para gravação da entrevista. Nisso, mesmo com o intermédio da associação, em um dado momento da pesquisa, a dona do Bar Da Geni recomendou gentilmente que não houvesse mais nenhuma visita ao estabelecimento.

As garotas de programa entrevistadas estavam inseridas no entorno da Rua Paissandu, na região Centro-Sul de Teresina. Sá Filho (2006) em seu estudo sobre a vida boêmia de Teresina, entre a década de 1930 e 1970 a região Paissandu é apontada como o cinturão de prostíbulos em Teresina. A capital expandiu-se economicamente nesse período impulsionado pelo comércio e as embarcações que ancoravam no Rio Parnaíba, ocasionando o crescimento comercial na região. Para Sá Filho (2006):

\begin{abstract}
Contrariando a abordagem hierarquizante da cidade a partir do centro como lugar de licitudes e disciplinas e as margens como lugar de transgressões e relações ilícitas, a Paissandu se constituiu como a mais tradicional zona boemia e de prostituição em Teresina sem estar fora do perímetro urbano, mas dentro dele. Fisicamente foi traçada como uma das vias de acesso para a parte mais central da cidade, partindo da margem do rio Parnaíba, com o nome de Rua do Pequizeiro, 26 e posteriormente recebendo a denominação de Paissandu. Com as ruas adjacentes, constitui-se na zona, de modo que a palavra Paissandu passou a significar não somente um nome de rua, mas o de baixo meretrício, local de prostituição. A partir dessa significação, no cotidiano da cidade, inventou-se a expressão "descer a Paissandu", que quando usado referindo-se a alguma mulher, não significava deslocar-se aquela via pública, mas tornar-se prostituta. (Sá Filho:56).
\end{abstract}

O entorno da Rua Paissandu ainda mantém uma gama de bordéis destinados àqueles indivíduos de classe social alta, média e baixa, compondo assim a zona boêmia teresinense. Na contemporaneidade, a principal diferença das décadas de 30 a 70 é o fato de que garotas de programa e os boêmios não mais esperam apenas o cair da noite para aparecerem. As prostitutas e seus clientes circulam no período diurno, mesclando-se com o cotidiano de pessoas que podem estar ali procurando ou não serviços sexuais ofertados na região. (PASINI, 2005; SÁ FILHO, 2006).

\title{
Reflexões acerca da prostituição e das "prostituições”
}

A prostituição é um dos serviços relacionados ao erotismo e prazer, este, passível de ser contratado e vendido. É possível encontrar inúmeras produtoras de conteúdos relacionadas à pornografia, tais como as cam-girls, jovens mulheres que oferecem serviços eróticos online para websites na internet, ou, ainda, aquelas que trabalham performando strip-tease em clubes noturnos. Contudo, todos os serviços elencados são confundidos com a prática da prostituição, sendo divergentes um do outro. Diante disso, deve-se ter cautela em não confundir exploração sexual com prostituição, pois, a ideia de exploração sexual é entendida como prostituição forçada, sendo, geralmente ligada ao trabalho sexual escravo e tráfico de pessoas e/ou quando a maior 
parte dos seus ganhos acaba ficando nas mãos dos cafetões e cafetinas, ou, ainda, existe uma alta cobrança de taxas para as garotas se manterem nas casas de prostituição. (PISCITELLI, 2005, 2013; RAGO, 2011, 2014)

A prostituição vem demonstrando várias facetas, sobretudo, com a liberdade sexual crescente desde a década de 60. A perspectiva acerca de prostituta como sendo reduzido a "uma mulher sentenciada a um destino cruel", transformou-se com a chegada de novas produções científicas, na qual, o enfoque era maior em seu cotidiano. Portanto, torna-se difícil falar da prostituição como uma unicidade, pois, a atividade adquire diferentes desenhos, variando de garotas universitárias a senhoras idosas até garotas de classe média alta, ou ainda, a garotas que se prostituem para suprir necessidades básicas. A prostituição naturalizada como mal necessário ou a profissão mais antiga do mundo deve ser pensada além desse discurso generalista, mas, sim, analisada como um fenômeno construído social e historicamente. (FONSECA, 1996; RAGO, 2011, 2014).

A própria visão da prostituição enquanto trabalho é conflitante entre autoras feministas. Enquanto o feminismo radical tem a prostituição como abuso e violência contra a mulher, restringindo sua liberdade e cidadania, além, de se configurar como uma total submissão feminina ao patriarcado. Posteriormente, em oposição à visão do feminismo radical, as feministas liberais (ou contratualistas) consideram a prostituição como um trabalho, uma vez que, a prostituta estabelece um contrato a partir de uma combinação, especificando um período de tempo e uma quantidade de dinheiro. Para o feminismo liberal, a prostituição deve ser encarada como um trabalho qualquer, pois, afinal, mantém a lógica do mercado capitalista, e, se torna uma transação comercial (PASINI, 2005b; PISCITELLI, 2013).

Diante disso, é importante ressaltar que existe uma diferença entre aqueles corpos que seriam prostituídos ou explorados sexualmente com corpos inseridos na prostituição devido à falta de acessos a serviços essenciais e bens de consumo (PASINI, 2005, 2005b; PISCITELLI, 2005, 2013). As etnografias de Pasini (2005 et al) e Alves (2010) mostravam algumas garotas que afirmavam estar na prostituição não somente pela necessidade financeira, mas, também, por gostarem do trabalho nas noites.

Esse polêmico debate em torno da prostituição tem como centralidade, ou ponto de convergência, o tipo de serviço que é oferecido, e, que, por sua vez, está associado diretamente ao uso do corpo ou mais precisamente a determinadas partes do corpo, a exemplo das partes íntimas e sexuais. Na prostituição, o uso do corpo como um todo tem sentido diferente do uso do corpo em outros trabalhos, a exemplo do trabalho burocrático realizado em empresas ou instituições públicas.

As garotas entrevistadas no campo rechaçam a imagem de vítimas e coitadinhas ${ }^{143}$, por tal, não se veem enquanto vítimas, mas, também, admitem que a prostituição não seria seu projeto de vida. Com exceção de Fátima ${ }^{144}$, as quatro garotas admitem ter entrado na prostituição pelo dinheiro rápido e por necessidades ligadas a motivações financeiras.

A prostituição feminina caracteriza-se como atividade na qual a garota vende serviços sexuais, sobretudo, $o$ ato sexual mediante valor previamente combinado com o cliente. O corpo não é visto como um objeto que será vendido, mas, sim, como uma ferramenta que mulheres inseridas na prostituição aprendem e fazem o uso de seus corpos para a realização do trabalho sexual.

Durante a incursão no campo é perceptível como as prostitutas tem controle do tempo e das atividades realizadas no bordel. Notou-se isso quando um grupo de rapazes contratou Graça para realizar um

\footnotetext{
143 Palavra dita por Graça ao se referir como os programas de televisão mostram as garotas de programa.

144 Diferente das outras quatro garotas entrevistadas, Fátima foi vítima de exploração sexual na infância quando a sua mãe se casou novamente. O novo companheiro da mãe de Fátima não aceitou os filhos do antigo casamento e decidiu doar Fátima e seus irmãos. A mulher que passou a criar Fátima explorou-a sexualmente dos 12 aos 15 anos de idade. Ao passo de que, a partir disso, compreende-se que todas as outras garotas ingressaram na prostituição em algum momento de fragilidade econômica sem o intermédio de nenhum rufião.
} 


\title{
GAROTAS DE PROGRAMA EM TERESINA: WaIIIOM

(1)

strip-tease, e, durante a apresentação a prostituta tinha total noção do tempo da apresentação e das partes do corpo que os contratantes poderiam tocar. Ao término, a garota vestia-se e saía da mesa dos clientes e voltava à busca de novos contratantes de seu serviço. (PASINI, 2005, 2005b; ALVES, 2010; PISCITELLI, 2013)

A partir de uma ótica estrutural e tendo em mente a sociedade capitalista baseada na compra e venda de trabalho, a prostituição assume um caráter mercantilista. Tendo em vista que nossa sociedade é voltada para a produção de mercadorias, sendo incluindo coisas e pessoas, de acordo com Albuquerque (2008):

\begin{abstract}
A prostituição se revela como um complexo que a) Assume responsabilidade de satisfazer necessidades sexuais do homem que não cabem no ambiente doméstico; b) Se articula com que o dinheiro é o mediador das relações humanas; c) representa uma manifestação de mercantilização típica da sociedade capitalista, em que como dizia Marx (2004b), o mundo das coisas é valorizado na proporção direta da desvalorização do mundo dos homens. É um contexto em que tudo é passível de se tornar mercadoria e os indivíduos se afirmam na sociedade justamente quando tem algo a vender ou comprar (Albuquerque, 2008:37).
\end{abstract}

A prostituição é articulada com o surgimento da família patriarcal, da propriedade privada e o Estado (instituição necessária para regular a vida social permeada por antagonismos indissolúveis). Portanto, ao considerarmos esta articulação, deve-se ressaltar que os elementos aparecem como um complexo reinscrevendo a maneira com que homens e mulheres produzam vida (ALBUQUERQUE, 2008). Com isso, a família acabou se tornando o mecanismo de produção e reprodução da propriedade privada, fazendo com que as mulheres ficassem enclausuradas no espaço doméstico para poder identificar o herdeiro da propriedade. A sexualidade tida como desviante passou a não mais ser tolerada em espaços públicos, mas, sim, reinscrita e exercida em certos espaços. (FOUCAULT, 2013; ALBUQUERQUE, 2008).

\section{Corpos e feminilidades: "descendo a Paissandu"}

A partir de Marcel Mauss (2017), o corpo deixou de ser objeto somente das ciências medicas e naturais, mas, também, objeto das ciências sociais, na qual, o corpo carrega significados e produz sentidos que aos poucos se cristalizam em nossa sociedade. Para tanto, é válido questionar: que corpo? Ou, melhor, que corpos permeiam as prostitutas em Teresina?

Nesse sentido, o corpo é visto de forma distinta, dependendo do contexto cultural e temporal. Em sociedades do tipo comunitária e/ou holísticas, o corpo é o elo que conecta o indivíduo a sociedade e ao ambiente (LE BRETON 2006, 2016). Portanto, o corpo não é uma ruptura entre o coletivo e individual, ou, ainda, aquilo que separa o indivíduo da sociedade, mas, sim, surgem como elementos totalizantes e interconectados.

Com o avanço das ciências biomédicas e da individualização da sociedade, este corpo na cultura ocidental passa a ser visto como o interruptor da ligação do indivíduo com a coletividade. Ainda, o corpo é visto como posse, algo que pertence ao sujeito, sendo, que, esse saber biomédico que lentamente anatomizou o corpo ainda se mantém presente atualmente.

David Le Breton (2016) realiza uma antropologia cosmológica e delineia a passagem do corpo popular para o corpo individual no ocidente. Sendo, este primeiro, uma alegoria carnavalesca que transgride e goza livremente dos prazeres, liberando suas pulsões despudorada e publicamente. Essa concepção choca-se diretamente com o corpo moderno, um corpo áspero, limpo, moral e privado:

Os órgãos e as funções carnavalescas serão pouco a pouco depreciados, tornados objetos de pudor, privatizados. As festas serão mais ordenadas, fundadas mais sobre a separação do que sobre a confusão. (Le Breton, 2016:39). 
A partir disso, podemos enxergar que a garota de programa não vende seu próprio corpo, mas, sim, o ato sexual. Aqui, para tanto, o corpo inserido na prostituição é de posse da garota de programa, sendo, portanto, aquilo vendido não uma parte do corpo ou órgão, porém, o serviço sexual combinado. Garotas de programa fazem o uso de seus corpos na realização dos serviços vendidos, tornando-se esta sua principal ferramenta de trabalho no exercício da prostituição feminina (PASINI, 2005 et al; LE BRETON, 2006, 2016; MAUSS, 2017; SIQUEIRA, 2013).

O corpo da garota de programa é tido como aquilo que os indivíduos, em sua maioria esmagadora homens, podem realizar com prostitutas, isto, sendo algo que não se pode fazer com a esposa, ou, ainda, a normativa de mulher construída no imaginário masculino como uma figura materna e protetora (LEONINI, 2004). Meihy (2015) reuniu em um livro, artigos sobre brasileiros e brasileiras inseridos no mercado da prostituição na europeia e estadunidense, reunindo um compilado com histórias de vida desses indivíduos. Partindo disso, faz-se necessário trazer o fragmento da entrevista de uma das participantes desta pesquisa, em que, exemplifica-se a percepção do corpo da prostituta enquanto algo destinado aos prazeres transgressores, que, muitas vezes, não podem ser praticados no âmbito doméstico:

Olha, ser puta, onde quer que seja não é boa coisa! A gente sofre muito, apanha, tem que aguentar fregueses de todo jeito, gente limpa, suja, doente, gordo ou magro, fedido. Tem tarado de todo tipo e é com a gente que eles dão vazão ao que não conseguem na vida. [...] Gastei meu carinho com todo tipo de baixaria no mundo. (Meihy, 2015:110).

A incursão etnográfica no entorno da Rua Paissandu demonstra com clareza a situação supracitada. As motivações de procura do cliente variam entre cada tipo, sendo possível traçar fatores de busca em comum. Pode-se elencar a facilidade para se "conquistar" uma mulher, liberar os desejos e pulsões tidos como ilícitos ou até a afirmação da própria masculinidade. No discurso das cinco entrevistadas isso se confirma, pois, o cliente tem uma visão carnavalesca e popular do corpo da garota de programa, este, sendo um corpo que por aquele breve momento poderá deleitar-se inteiramente (LEONINI, 2004). Contrariamente, a percepção dos clientes, no trabalho de campo se mostrou a predominância da visão das prostitutas como sendo donas dos seus corpos, e, que, certas práticas não são ou serão realizadas ${ }^{145}$ como exemplos a seguir:

Agora, assim, eu só não saio com mulher. Eu posso sair para o cara me pegar e pegar ela. Ou, então, pra ela vir me chupar (tom de voz mais baixo), agora, eu chupar ela, eu não consigo, amigo, já perdi muito dinheiro com isso, eu não consigo. Não vai... Entendeu?! [...] Eu queria saber gostar de fazer tudão. Agora... aquela coisa... assim, garota de programa não se cuida faz tudo. (Graça, 28)

Ele ficou louco (bêbado), e eu fiquei do lado dele. Ele se acordou, eu mandei ele tomar um banho e aí ele disse "a gente transou pelo menos?" e eu respondi "transamos, fizemos foi tudo, amor". Botei ele aqui (aponta para uma cadeira na boate) sentei com ele, depois fui até o carro dele, já vi que ele tava nas condições bacanas de dirigir e foi embora [...] . (Fátima, 38)

Os clientes tem a falsa impressão de que o corpo da garota é livre para realizar qualquer prática, isso, logo após a compra do serviço sexual. Quando imersos numa relação social, símbolos verbais e não verbais são incorporados e usados propositalmente, de forma consciente ou inconsciente, a fim de construir uma impressão que será emitida através das expressões realizadas pelos sujeitos. Os indivíduos que estiverem se relacionando naquele momento poderão vestir-se da persona mais adequada para determinado contexto.

${ }^{145}$ A mais conhecida popularmente e citada na bibliografia especializada e no trabalho de campo é o beijo na boca. 
E, todos os envolvidos na interação, seja o ator ou a plateia, entrarão no jogo teatral tentando esboçar uma impressão adequada para aquele momento. Garotas de programa usam o corpo como ferramenta para lidar com os clientes durante e após a combinação do programa (GOFFMAN, 1985; CUNHA, 2012).

O corpo da garota de programa pertencente a ela, porém, seu principal instrumento de trabalho experimenta antes de seu uso uma produção voltada para o trabalho na prostituição. Se o corpo é posse única e individual da garota, o mesmo já não pode ser dito sobre a produção corporal exercida. O corpo produzido pela cultura é moldado de acordo com o contexto temporal e cultural, fazendo com que corpos produzam e reproduzam discursos. Mais que um conjunto de musculatura, o corpo também é a roupa, os acessórios que o adornam, os processos cirúrgicos que nele se operam, assim como, a imagem e o sentido produzidos no corpo, as máquinas acopladas e sua gestualidade. (GOELLNER, 2004; ROSTAGNOL, 2004).

O corpo pode ser encarado como um local pelo qual perpassa a formação de nossa identidade, e, portanto, aquilo que desejamos expressar através da corporeidade. Podem-se destacar certos aspectos em uma primeira instância, mas, que podem ser discrepantes com outras identidades vivenciadas pelo indivíduo. Para Goellner (2004):

A individualização das aparências produzidas [...] tem levado os indivíduos a perceber que o corpo é o local primeiro da identidade, o locus a partir do qual cada um diz do seu íntimo, da sua personalidade, das suas virtudes e defeitos. [...] Um eu construído a partir de referências inscritas e prescritas em diversas instâncias culturais. [...] A produção do corpo se opera simultaneamente no coletivo e no individual. (Goellner:39)

O corpo construído pelas entrevistadas não é algo uniforme entre elas, por isso, durante suas falas é perceptível como diferentes locais e contextos de prostituição geram produções específicas. Os corpos das cinco entrevistadas são todos produzidos tendo como base o gênero feminino, todas as cinco entrevistadas são mulheres cujas identidades de gênero estão em "sintonia" com seu corpo biológico ditado pelo saber biomédico e normatividade heterossexual. São corpos femininos que foram constantemente generificados por meio de normas sociais e por iniciativa própria. Para Connell (2015):

Assim, não podemos pensar o ser mulher ou o ser homem como experiências fixadas pela natureza. Mas também não podemos pensa-los apenas como uma imposição externa realizada por meio de normas sociais ou da pressão de autoridades. As pessoas constroem a si mesmas como masculinas ou femininas. Reivindicamos um lugar na ordem de gênero - ou respondemos ao lugar que nos é dado - na maneira como nos conduzimos na vida cotidiana. (Connell, 2015:39).

Entre as entrevistadas era presente a busca por características, estas tidas como femininas na produção do corpo. Contrariando os corpos de mulheres transexuais, cujas alterações corporais visam afastar as características masculinas do corpo, e, por fim, substituí-los pelas femininas. Isso ocorre porque mulheres transexuais estão constantemente sendo forçadas a provar sua "feminilidade". Enquanto isso, a produção corporal das prostitutas entrevistadas apresenta motivações mercadológicas e de cuidado com o próprio corpo, isso, em contra partida as prostitutas transexuais, sua feminilidade não é continuamente contestada (BENEDETTI, 2005).

Os corpos das prostitutas entrevistadas não sofrem contestações à dubiedade de sua condição enquanto mulher, mas, sim, são expostos à exclusão social ou violência, pelo fato de utilizarem seus corpos para comercializarem o próprio sexo. A diferenciação frente ao outro se imbrica na dualidade reproduzida socialmente da mulher doméstica e a mulher da rua (BUTLER, 2000; SANTANA \& AZEREDO, 2013; CONNEL, 2015). E, por serem percebidas e genereficadas como mulheres desde o nascimento, a produção do corpo nas entrevistadas 
não são tão radicais ${ }^{146}$, justamente por ter o seu gênero dentro da norma regulatória hegemônica. $\mathrm{O}$ nível da produção é uma mescla de subjetividade da própria garota com intenções previamente estabelecidas.

Graça e Fátima são as maiores investidoras em produção corporal entre as entrevistadas. $\mathrm{O}$ valor cobrado pelas garotas era entre 100 - 150 reais, tendo em vista, que, um valor menor poderia desvalorizar a casa segundo as entrevistadas. Graça ostenta um corpo voluptuoso em todos os sentidos: os seios, nádegas e coxas são abundantes e bem torneados, enquanto o brilho final no corpo é o piercing acoplado no umbigo. A garota de programa durante a entrevista relata com orgulho sobre a realização de intervenções cirúrgicas de cunho estético:

[...] na Venezuela nosso dinheiro e valorizado, não é que é barato, nosso dinheiro é mais, é muito valorizado lá. Eu fiz abdominoplastia, lipo, limpei costa, limpei perna, braço, botei silicone no peito, fiz tudo por seis mil reais enquanto aqui no Brasil ficaria 30,000. (Enquanto falava a garota apontava para as partes do corpo citadas.). (Graça, 28).

Graça em um momento admitiu já ter feito uso de anabolizante, pois, segundo a mesma: "sai do corpo naturalmente". A garota frequenta academia diariamente e busca ocasionalmente ter uma alimentação balanceada. Outro aspecto importante é o vestuário escolhido. Graça, assim como as outras garotas do Hilda Drink’s ou que trabalham nas boates, dão preferência por roupas curtas e apertadas. A marca de Graça são seus vestidos em tons de rosa ou vermelho chocante com aberturas para evidenciar suas tatuagens. Durante a observação, as tatuagens vistas foram uma no pulso, uma na costela e uma de ponta a ponta na barriga na altura do umbigo. A tatuagem além de recurso para chamar atenção dos boys ${ }^{147}$ servia para esconder as cicatrizes de cirurgias plásticas realizadas. O cabelo é loiro platinado e segundo ela característica essencial para a conquista de clientes.

Eles gostam é do cabelo loiro. Nossa, na hora que eu passo jogando esse cabelo loiro eles já falam "Ei, loira, quanto tu cobra? Ei, loira, senta aqui". [...] Aqui a menina pode ser preta o que for, a própria escuridão, mas tem que ser loira. É até bom que eles comem uma loira e morena ao mesmo tempo (risos da interlocutora) (Graça, 28).

A fala de Graça sobre mulheres loiras no bordel é confirmada, pois, dando qualquer olhada mais atenta, já é possível revelar a predominância de mulheres com cabelos loiros no Hilda Drink's. Neste momento, percebemos a entrada de um novo fator, sendo a produção de seu corpo, também, acabando por perpassar e se arranjar pelas técnicas apreendidas sobre a sedução da clientela. Graça aponta que o truque para conquistar o cliente é a fala da putaria.

Assim, ele chega... a gente tem que ir ao ataque, né filho?! [...] E homem gosta de putaria. Entendeu?! Tu falando putaria pra ele, meu filho, ele já se empolga. Entendeu?! "ai e memo loira, tu faz isso, tu faz isso...?" Aí eu respondo: "Ai, eu faço gostoso, chupo, tu gosta daquelas lambidas, daquelas coisas...?!" Aí o homem fica doido. Já começa, "quanto é teu programa, loira?”. “Tanto!”. Já era. Já tá na linha, vamo embora. (Graça, 28)

Fátima deixa claro que não tem necessidade de fazer cirurgias plásticas, mas, admite que ao contrário de algumas garotas, não consegue trabalhar com uma calça jeans e sandálias, pois precisa do salto alto. O processo de produção de Fátima é amplo: a maquiagem sempre forte, batons em cores vibrantes e

\footnotetext{
${ }^{146}$ Benedetti (2005) relata como travestis buscam profissionais clandestinas chamadas de "bombadeiras" que injetavam silicone industrial em travestis e transexuais visando dar ao corpo um contorno mais feminino através do aumento dos seios e das nádegas.

${ }^{147}$ Forma como as garotas chamavam os potenciais clientes ocasionalmente
} 
sombras carregadas no olhar. Independentemente do horário, Fátima sempre está adornada com colares e anéis em quase todos os dedos, as unhas sempre feitas, também, e, em cores chamativas. O cabelo loiro platinado em contraste com a pele negra finaliza o visual exuberante e belo da garota de programa.

O corpo de Fátima está longe de ser inserido dentro dos padrões contemporâneos estéticos que pregam um ideal de corpo magro, simétrico, jovial e saudável (GOELLNER, 2004). Fátima é uma mulher obesa, negra e com alguns dentes a menos. Quando entrevistada Fátima nos explica que um de seu atrativo para a sedução está na dança. O corpo de Fátima é todo produzido e voltado para a conquista, não visando comercializar o ato sexual em si, mas, sim, sua dança. Fátima ostenta o título de Fafá Tsunami, pois, segundo a mesma, sua dança não é uma dança qualquer, mas, sim, uma "coisa de profissional, uma apresentação toda planejada".

[...] mas eu gosto é de dançar, eu prefiro fazer dez shows na noite que deitar com um homem na noite. Porque só na minha dança eu tiro o dinheiro de dois, ou três, ou quatro programas. Só na dança. [...] eu faço pole, eu danço aqui... Na verdade, eu sou profissional de dança. Eu fecho contrato nas casas, só que aqui quando eu vim fechar o contrato na época, aí ela deu valor em mim uma semana na outra semana e depois já não queria mais dar, aí eu passei a arrecadar as mesas. A gente dança duas vezes na noite e arrecada tudo na mesa, e quando eu faço programa é com um único homem. Digamos que se uma menina faz dez programas para ganhar $\mathrm{R} \$ 1,000$ à $\mathrm{R} \$ 100$, eu faço programa com o único homem para sentar do lado dele... Não preciso fazer dez programas. [...] assim... é difícil de te explicar isso aí, mas, eu tenho, digamos, uma lábia que faz o homem me dar até as calças dele. (Fátima, 38).

Para Fátima, dançar é a melhor forma de conseguir dinheiro da clientela. Outra estratégia para arrecadação de dinheiro é o uso do charme que a garota de programa denomina de dengo. Durante a observação noturna no Hilda Drink's, houve a oportunidade de observar a dança de Fátima. O corpo belo e rechonchudo da garota dançava as músicas lentas com batidas eletrônicas que remetiam a sensualidade, o vestuário formado por uma capa em tecido fino translucido e um vestido curto, deixando parte das ancas à mostra e uma calcinha de renda preta quase transparente, que, iam desaparecendo vagarosamente a meia luz vermelha, até ficar completamente nua restando apenas uma máscara. A garota realizava acrobacias e saltos envolvendo cadeiras e cambalhotas em cima de um salto alto. Em um dos pontos chave de sua dança, Fátima dava cambalhotas múltiplas ao redor do palco circular localizado no meio da boate. A finalização do show de Fátima acontecia ao som da música "Abandonada" da cantora paraense Fafá de Belém, nesse momento, é impossível não associar a letra com a trajetória pessoal de Fátima; marcada pelo abandono da mãe na infância, o abandono do ex-marido, de uma antiga companheira amorosa e de um cliente por quem nutriu uma paixão.

A prática do dengo segundo Fátima, seria fazer uma espécie de charme e ao mesmo tempo se colocar em uma posição passiva e infantil perante o cliente, visando conquistá-lo. Contudo, tornar-se uma mulher dengosa, segundo Fátima, era preciso estar bêbada. O consumo de bebidas alcoólicas é frequente no Hilda Drink's, mas, das cinco entrevistadas, apenas Fátima e Ângela revelaram quando ébrias, ou, muito loucas, é que o trabalho tem maior rentabilidade.

Amélia é a mais nova das garotas entrevistadas, que, na época da entrevista, tinha 22 anos, e, está há um ano na prostituição. A produção de Amélia é bem menos complexa que a de Fátima e Graça. Amélia diz não malhar todo dia, somente quando tem vontade, e, que, ao contrário de outras garotas, não sente vontade de fazer nenhuma intervenção cirúrgica. O corpo de Amélia também é composto por seios e quadris fartos devidamente bronzeados, na qual, a garota trata de exibir as marcas de sol referentes ao procedimento. Todavia, Amélia diz investir pesado em tratamentos corporais no salão de beleza e clínicas de estética. 
Unha, cabelo, limpeza de pele, tudo para ficar bonita a gente tem que fazer porque a gente trabalha com o nosso corpo. [...], a gente tem que fazer propaganda com ele [...] tem cliente mesmo que a gente tem acesso assim ao contato, aí no dia que eu "faço a marquinha" eu vou tirar foto “Olha, eu fiz marquinha!”. Ele vem correndo. É dinheiro garantido. (Amélia, 22).

Amélia afirma que a produção em seu corpo é de acordo com o dia da semana e, que, a produção se intensifica a partir da quarta-feira, quando a boate passa a ser mais frequentada, segundo ela.

É, porque segunda-feira não dá ninguém entendeu o que vier é lucro, mas não dá ninguém, ninguém, ninguém, ninguém, mesmo. Então, tipo assim, eu tô aqui assistindo televisão aí eu janto, aí eu fico, não tem nada para fazer, aí eu vou boto um short jeans, uma havaiana e vou para aí, fico sentada na porta conversando, e tu acredita que é um dia que eu mais trabalho quando eu me visto desse jeito?! [...] Vamos supor, uma quinta-feira aqui lota se eu chegar "porra, tô com preguiça, vou me arrumar só meia-noite!" e aí se eu pegar uma blusinha, um shortinho, uma havaiana e sentar bem ali, eu trabalho mais do que se eu tiver toda arrumada. Te juro! Às vezes vou de baby-doll. (Amélia, 22).

Amélia relata que não toma iniciativa durante o trabalho, preferindo ficar sentada em um canto, esperando o cliente chamar. Durante a observação noturna, em um dia de sábado da na boate, a jovem trajava um vestido tubo azul marinho, bem vibrante, e, alguns colares dourados. A maquiagem formada por tons neutros (ou às vezes nem maquiada), com exceção do batom vermelho, e, novamente, o piercing prateado à mostra.

\begin{abstract}
Eu só uso batom vermelho. Tem uns dias, vamos supor, dia de quinta à sexta, e, sábado são os mais movimentados, então, são esses três dias que eu pretendo que me arrumo mais. Porque se for segunda... Segunda-feira não me arrumo de jeito nenhum, do jeito que eu tô eu fico aqui no salão, aí dia de terça eu arrumo um pouquinho, mas eu não preciso botar salto. Boto uma sapatilha, uma havaiana, qualquer coisa. Quarta-feira já me arruma um pouquinho, a coisa já começa a melhorar. São dias que eu me arrumo melhor para trabalhar. Quinta, sexta e sábado são os dias que eu me arrumo melhor pra trabalhar. (Amélia 22).
\end{abstract}

Quando um cliente contratou o serviço de dança da Amélia, foi perceptível algo que pôde ser captado durante toda a entrevista, o jeito cativante e infantil de Amélia alegrava o ambiente, tudo ao som de pagode. Quando perguntada sobre o uso de alguma estratégia para conquistar o cliente, Amélia diz não ter nenhuma, apenas fica sentada esperando o cliente tomar iniciativa, devido à timidez. No corpo de Amélia existe uma circunscrita, ou melhor, uma proteção religiosa através das duas tatuagens de São Jorge. Quase no final da entrevista Amélia relata não saber se seu jeito infantil, ou, como denominado por ela, "meninona", acaba por servir como atrativo, em que, ela diz apenas ser assim.

Ângela e Rita são as garotas que trabalham na rua, ou, como chamado por Ângela, "bater pista". Na prostituição de rua, o cliente quando contrata um programa paga dez reais pelo valor do quarto ${ }^{148}$ ou o programa pode ser feito no carro dele, e, caso o cliente estiver disposto a pagar mais, pode levar a garota para um motel.

Ângela anteriormente trabalhava nas noites em um bordel mais luxuoso da cidade, ela passou a trabalhar no entorno da Rua Paissandu poucos meses da data que foi realizada a entrevista. O divisor de águas para a saída de Ângela do fervo da noite teresinense para o calor das pistas do centro foi sua saúde:

${ }^{148}$ As garotas de programa iam para os quartos na maioria das vezes no Bar Da Geni ou no Pé de Banana (outro bordel da região). 
[...] eu fiquei com muito medo! Eu dei um apagão depois de fumar quatro baseados e uma única dose de uísque com Red Bull. Quer dizer, meu corpo já não tava mais aguentando. Eu tomava doses e mais doses e doses incontáveis de uísque e era para mais de dez baseados. Aí, com quatro desmaiei, com quatro e uma dose! Aí eu me assustei. (Ângela 27)

Quando trabalhava no período noturno, Ângela denominava a si mesmo de Gata Raiada ${ }^{149}$ e toda patricinha. Ela conta que investia pesado em se produzir para a noite, sendo, sempre comum ir de vestido, devidamente maquiada com salto alto e perfumada. O investimento no corpo para o serviço na noite era válido devido ao retorno financeiro, assim como Fátima, Ângela também precisava do uso do álcool para ficar acesa. No caso de Ângela, tinha o acréscimo do uso de maconha em seu processo de produção. A mesma relata que sem o uso da maconha ou bebida alcoólica não conseguia exercer o trabalho na prostituição.

A produção do corpo para trabalhar nas ruas de dia é mais modesta, as roupas ainda são curtas, mas, simples. Elas podem tanto ser abordadas pelos clientes quanto elas podem chamá-los. O próprio contato com Ângela aconteceu no momento em que ela assobiou para mim, visando realizar um programa. A razão da produção mais modesta é que o valor cobrado pelo programa é entre 60 - 80 reais, logo, não são válidos gastar dinheiro com perfumes ou roupas mais caras.

[...] eu passo protetor solar, protetor facial e protetor corporal, são dois tipos diferentes por isso que esse negócio é caro. Eu faço uso do hidratante para pele não ficar craquelada e também para dar cheiro porque eu dispenso perfume durante o dia por vários motivos: motivo número um, o programa: que dia é barato. Motivo número 2: Perfume é forte e me dá dor de cabeça. Motivo número 3: durante o dia eles estão indo e vindo do trabalho eles vão passar em casa então não é bom ficar cheiro de perfume neles? Então por esses motivos eu não uso perfume durante o dia. [...] só batom não boto o lápis de olho, não boto o rímel, nada, nada, só batom e as unhas feitas sempre. Toma cuidado das unhas ficarem feitas o cabelo retocado a tinta né?... E eu tomo cuidado de mexer com aparência, roupa simplesinha chamando atenção curta mostrando o bundão o periquito só isso. Tomar esses cuidados. (Ângela, 27)

A produção de Rita é bem similar à de Ângela para as ruas, pois, o processo de produção de seu corpo também passa pelo estágio do consumo de bebidas alcoólicas para seduzir os clientes. Durante o dia, a garota prefere também faz uso de roupas mais simples e quase não usa maquiagem. Contudo, à noite Rita afirma se produzir com mais intensidade e investir em maquiagens e batons que ressaltem sua pele branca e seus olhos esverdeados, além, de sempre usar um vestido vermelho.

O corpo na prostituição diurna nas ruas é menos deslumbrante, mas, igualmente desejado. Le Breton (2016) analisa o corpo posto na vida cotidiana dos indivíduos e como este revela as contradições com uma norma imposta estabelecida. A lógica da imagem de um corpo desejável se transforma, fazendo daquele corpo excluído, um corpo desejado. Os clientes em sua maioria são como constata Leonini (2004), "homens normais": pais de família, senhores aposentados ou filhinhos de papai ${ }^{150}$. Estes, jovens vistosos a procura de corpos marginalizados e apagados cultural e socialmente.

As ruas da região da Rua Paissandu abrigam uma infinidade de corpos que de alguma forma são estigmatizados e que nunca são propagados como objeto de desejo sexual pela grande mídia: corpos despeda-

\footnotetext{
${ }^{149}$ A expressão remete a garotas ou mulheres dispostas a se divertir durante toda a noite, seja dançando, fazendo uso de drogas ou bebendo.

${ }^{150}$ Expressão utilizada pelas garotas para denominar um jovem com perfil universitário sustentado pelos pais com idade na faixa dos 17 a 25 anos.
} 
çados, corpos com deficiência mental, corpos em completa fora de forma, corpos idosos. Em síntese, corpos femininos desiguais partilhando um mesmo espaço em busca de sobrevivência (FONSECA, 1996).

Os procedimentos de cuidado com a saúde do corpo é unanime entre as entrevistadas, para tanto, todas afirmaram fazerem o uso de preservativos nas práticas sexuais ${ }^{151}$. As cinco mulheres entrevistadas revelaram fazer acompanhamento ginecológicos, e, em especial uma, Amélia, que afirma se prevenir fazendo o uso de pomada vaginal e antibiótico. Amélia e Graça dizem realizar a chuca ${ }^{152}$ para não sujarem os clientes e a si mesmas durante $\mathrm{o}$ ato do sexo anal

\section{Considerações finais}

Distante de ser algo eventual, o investimento que garotas de programa fazem sob seu corpo se imbrica dentro de uma lógica que busca maiores rendimentos com o trabalho na prostituição. Visto que mesmo aquelas garotas não efetuando produções complexas em seus corpos, é unanime a principal motivação da investidura de tempo e dinheiro no cuidado, e, na construção de seus corpos para a prostituição sendo o dinheiro. Durante o cotidiano nas boates, quando perguntadas sobre qual seria a principal motivo para terem se inserido na prostituição, todas ressaltaram o aspecto financeiro. Graça frisa "é um dinheiro que vem rápido, mas que não é fácil e que se a garota não tiver cuidado vai rápido também”.

Todas as garotas entrevistadas atribuíram à prostituição o sentido de vício relacionado ao dinheiro faturado, como relatado por Amélia "quanto mais tu ganha, mais tu quer!". Acredita-se que a prostituição é a alternativa concreta encontrada por muitas mulheres para conseguir sobreviver ou aumentar sua renda, podendo assim, adquirir bens de consumo e serviços. Além de compras para si mesmas, as cinco entrevistadas revelaram que o dinheiro também ajuda no cuidado com os filhos, mães, pais e afilhados (FONSECA, 1996; PISCITELLI 2013).

Portanto, o corpo é a principal ferramenta de trabalho das garotas entrevistadas, além, também, de ser através dele que realizam todo o trabalho na prostituição, independentemente se o serviço seja a comercialização do próprio sexo ou apenas uma companhia para um homem enquanto esse consome alguma bebida. Este corpo na modernidade é construído e incorpora traços culturais contraditórios entre si, uma bricolagem individual que mescla traços do saber midiático, médico e de causalidades ocorridas no percurso da vida do indivíduo.

Na prostituição, o uso do corpo tem uma dimensão fortemente sexual e o exercício dessa sexualidade que associada à "mulher da rua" não se assenta e nem comunga com o que é considerado normal, legítimo, aquilo que pode ser publicizado ou apresentado em público como fazendo parte da família. Todavia, essas mulheres são desejadas pelos homens como instrumento de subversão e novidade diante da normalidade das relações conjugais, casamento ou família. Trata-se de sexo mais prazeroso, apimentado, salgado, porém, indigesto e problemático, sendo melhor evitar (DAMATTA, 1984; LE BRETON, 2016).

O corpo das entrevistadas não é dotado de signos que expressem somente significados atrelados à sensualidade, ao prazer ou aquilo que é transgressor. Seus corpos podem carregar suas proteções religiosas ou até seus próprios filhos através de adornos discretos ou tatuagens ${ }^{153}$. O corpo e sua produção revelam

\footnotetext{
${ }^{151}$ As cinco entrevistadas relataram fazer o uso do preservativo para todas as práticas sexuais, incluindo sexo oral ou quando as garotas vão penetrar os clientes com as mãos ou algum objeto. Graça inclusive ironiza na entrevista e nas conversas como as mulheres prostitutas são as mais precavidas visto que segundo ela no cotidiano outras meninas tidas como de família não se protegem totalmente durante as relações sexuais.

${ }^{152}$ Chuca é a forma popular para se referir a enema, prática que consiste na introdução de água no ânus para lavagem intestinal.

${ }^{153}$ Graça tinha em seu corpo o nome de seus dois filhos tatuados no pulso. Amélia ostentava a tatuagem de um terço além de ter consigo no quarto a imagem de São Jorge.
} 
não somente o investimento perpetuado visando lucro, mas, também, signos que à primeira vista podem parecer ambíguos, porém, demonstram a expansão da prostituta para além dos bordéis, boates ou ruas (FONSECA, 1996; HALL, 1999; RAGO, 1998, 2011; LE BRETON, 2016).

\section{Referências}

ALBUQUERQUE, Rossana Maria Marinho. 2008. Para além da tensão entre moral e economia: Reflexões sobre a regulamentação da prostituição no Brasil. Maceió-AL: Dissertação de mestrado em Sociologia Universidade Federal de Alagoas.

ALVES, Fabio Lopes. 2010. "Prostituição feminina, gênero e sexualidade: notas etnográficas de uma noite no bordel”. In: II Seminário Nacional de Sociologia e Política. Curitiba. Anais do II Seminário Nacional de Sociologia e Política. 03-25.

BEAUD, Stephanie.; WEBER, Florence. 2014. Guia para a pesquisa de campo: Produzir e analisar dados etnográficos. Petrópolis: Vozes.

BUTLER, Judith. "Corpos que pesam: sobre os limites discursivos do 'sexo". In: LOURO, Guacira Lopes (org). 2000. O corpo educado: pedagogias da sexualidade. Belo Horizonte: Autêntica. P151-172

CONNELL, Raewyn. 2015. Gênero: uma perspectiva global. São Paulo: nVersos.

CUNHA, Maria João Mendes Da. 2012. Vivências do Corpo na Prostituição Feminina. Coimbra-PT: Dissertação de Mestrado Integrado em Psicologia da Educação, Desenvolvimento e Aconselhamento - Universidade de Coimbra.

DAMATTA, Roberto. 1986. O que faz o brasil, Brasil?. Rio de Janeiro: Rocco.

FONSECA, Claudia. 1996. "A dupla carreira da mulher prostituta". Revista Estudos Feministas n.1. 07- 33.

FOUCAULT, Michel. 2013. A história da sexualidade I: A vontade de saber. Rio de Janeiro: Graal

GOELLNER, Silvana Vilodre. 2003. "A produção cultural do corpo”. In: GOELLNER, Silvana Vilodre; LOURO, Guacira Lopes; NECKEL, Jane Felipe (Org). Corpo, gênero e sexualidade: um debate contemporâneo na educação. Petrópolis: Vozes. P28-40.

GEERTZ, Clifford. 2008. "Uma descrição densa: Por uma teoria interpretativa da cultura" In: A interpretação das culturas. Rio De Janeiro: LTC. P25-41

GOFFMAN, Erving. 1985. A representação do eu na vida cotidiana. Petrópolis. Vozes

HALL, Stuart. 1999. A identidade cultural na pós modernidade. Rio De Janeiro: DP\&A.

LE BRETON, David. 2006. A sociologia do corpo; Petrópolis: Vozes.

LE BRETON, David. 2016. Antropologia do Corpo e modernidade. Petrópolis: Vozes.

LEONINI, Luisa. 2004. "Os clientes das prostitutas: Algumas reflexões a respeito de uma pesquisa sobre a prostituição em Milão”. In: SCHPUN, Mônica Raisa (Org.) Masculinidades. São Paulo: Boitempo Editorial. P70-107.

LIBÓRIO, Renata Maria Coimbra. 2005. "Adolescentes em situação de prostituição: uma análise sobre a exploração sexual na sociedade contemporânea”. Psicologia, Reflexão e Crítica. V. 18, N. 3. 413-420 
MAUSS, Marcel. 2017. “As técnicas do corpo”. In: Mauss, Marcel (Org.) Sociologia e Antropologia. São Paulo: Ubu. P421-441.

MAY, Tim. 2004. Pesquisa Social - Questões, métodos e processos. Porto Alegre: Artmed

MEIHY, José Carlos Sebe Bom. 2015. Prostituição á brasileira: Cinco histórias - São Paulo: Contexto.

MORAES, Aparecida Fonseca. 2014. "O corpo prostituído nas práticas discursivas de organizações dos direitos humanos”. In: GOLDENBERG, Mirian. (Org.). Corpo, envelhecimento e felicidade. Rio de Janeiro: Civilização Brasileira. P199-230.

PASINI, Elisiane. 2000. "Limites Simbólicos Corporais na prostituição feminina”. Cadernos Pagu, Campinas, v. $14,181-200$

PASINI, Elisiane. 2002. "Prostituição e Diferenças Sociais”. In: ALMEIDA, Heloísa; COSTA, Rosely Gomes.; RAMIREZ, Martha; SOUZA, Érica. (Org.). Gênero em Matizes. São Paulo: Editora da Universidade São Francisco. P81-114.

PASINI, Elisiane. 2005. "Sexo para quase Todos: a prostituição feminina na Vila Mimosa". Cadernos Pagu. v. $25,185-216$

PASINI, Elisiane. 2005b. "Prostituição e a liberdade do corpo". CLAM - AMB. 01-09

PISCITELLI, Adriana. 2005. “Apresentação: gênero no mercado do sexo”. Cadernos Pagu v. 25, 07-23

PISCITELLI, Adriana. 2013. "Exploração sexual, trabalho sexual: noções e limites”. In: SILVA, Daniele Andrade; HERNÁNDEZ, Jimena de Garay; SILVA Junior, Aureliano Lopes da; UZIEL, Anna Paula (Org.). Feminilidades, corpos e sexualidade em debate. Rio de Janeiro: EDUERJ: P147-165.

RAGO, Margareth. 2011. “A prostituição ontem e hoje”. In: GRILLO, José Geraldo Costa; GARRAFONI, Renata Senna; FUNARI, Pedro Paulo Abreu (Org.). Sexo e violência: realidades antigas e questões contemporâneas. São Paulo: Anablume. P212-225.

RAGO, Margareth. 2014. Do Cabaré ao lar: a utopia da cidade disciplinar: Brasil 1890-1930. São Paulo: Paz e Terra.

ROSTAGNOL, Susana. 2004. "Producidas para el amor: Estetica corporal de las prostitutas callejeras". In: LAGO, Maria Coelha de Souza; GROSSI, Miriam Pillar; ROCHA, Cristina Tavares Da Costa; GARCIA, Olga Regina Zigelli; SENA, Tito (org.). Interdisciplinaridade em diálogos de gênero: Teorias, sexualidades, religiões. Florianópolis: Ed Mulheres. P152-161.

SÁ FILHO, Bernardo Pereira. 2006. Cartografias do prazer: Boemia e prostituição em Teresina. Teresina-PI. Dissertação de mestrado em História, Universidade Federal do Piauí.

SANTANA, Dorotea; AZEREDO, Sandra. 2014. "A produção discursiva da prostituta como diferença e a construção de novas (?) faces da prostituição". GÊNERO. v. 14, n.1. P89-110.

SIQUEIRA, Indianara. 2013. "Profissionais ou "marginais" por falta de regulamentação". In: SILVA, Daniele Andrade; HERNÁNDEZ, Jimena de Garay; SILVA Junior, Aureliano Lopes da; UZIEL, Anna Paula (Org.). Feminilidades, corpos e sexualidade em debate. Rio de Janeiro: EDUERJ: P166-174. 